\title{
Communicating with Informal Sector Clients: A study of Strategies Employed by Ghana Commercial Bank and Unibank Ghana Limited
}

\author{
Denise D. Duncan \\ Correspondence: Department of Communications Studies, Central University College, Ghana \\ Received: April 22, 2015 Accepted: May 13, 2015 Online Published: January 22, 2016 \\ doi:10.11114/smc.v4i1.1329 \\ URL: http://dx.doi.org/10.11114/smc.v4i1.1329
}

\begin{abstract}
Even though theoretical evidence exists that tells of the need for effective communication between banks and their informal sector clients, little seems to be understood about the exact nature of communication between the two. Guided by the two-way symmetrical model and the communication accommodation theory this study set out to identify the communication strategies used by Ghana Commercial Bank and Unibank Ghana Limited in communicating with their informal sector clients in building mutually beneficial relationships. The objective was to identify and describe the specific communication strategies used by Ghana Commercial Bank and Unibank Ghana Limited to communicate with those clients. The study employed the in-depth interview method in gathering data as well as documentary analysis. The study found that the communication strategies employed by the two banks included using relationship managers as well as employing the technique of code-switching or using languages the client understood when communicating with the informal sector clients. The medium through which strategies were channelled included face to face interactions during workshops and banking clinics, telephone calls and regular visits from the bank officials known as relationship managers. These strategies helped both banks to promote mutual understanding and establish mutually beneficial relationships with their informal sector clients.
\end{abstract}

Keywords: communication strategy, code switching, informal sector, communication, relationship managers, bank

\section{Introduction}

Communication strategies adopted by Ghana Commercial Bank and Unibank Ghana Limited to engage individuals and small and medium scale enterprises operating within the informal sector was the focus of this paper. The informal sector according to Hart (1976) covered a wide range of labour market activities. According to the World Bank (2004), informal sector workers are people who are either self-employed or work as masons, carpenters, farmers, fishermen, potters, carvers, steel benders and small-scale plumbers belong to the informal sector. The informal sector again refers to traders, house-wiring electricians, funeral undertakers, night soil carriers, refuse collectors, traditional/herbal healers, attendants in private maternity homes, and traditional birth attendants among others.

The management of corporate communication is undertaken in a strategic manner by organising the corporate communication function including building support systems, in such a way that corporate objectives are met and the organisation including the bank as a whole is served (Cornelissen, 2004). To Cornelissen, communication strategies help companies including banks to propagate information in a structured and controlled manner. An ideal strategy details the structure of information flow, the message, the correct audience to address, potential vehicles to carry the message, resources required to fulfill that communication strategy, and feedback mechanisms to learn from the whole exercise.

In Ghana, 89 percent of the labour force is employed in the informal sector (Muwonge, Obwona and Nambaayo, 2007). In recent years, savings and loans companies such as Opportunity savings and loans limited and Procredit savings and loans limited have increased deposit mobilization from the informal sector. This has forced older players to begin looking further downstream at the informal sector. This is because banks now take into consideration or realise the need to open up their services to wider markets. They have begun to employ new and innovative communication strategies to win over hitherto untapped markets and the opportunities that come with them. Such banks design messages that are easily understood by clients and use appropriate media to convey these messages. 


\section{Material Studied /Literature Reviewed}

\subsection{Dialoguing with the Unbanked}

Rootman, Tait and Bosch (2007) conducted a study on some banks in South Africa whose major challenge was to find ways and means of catering for the unbanked segment in the South African population. It has been indicated that most banks deny the informal sector client of banking services especially loans as the sector has poor record keeping abilities. The banks studied were Amalgamated Banks of South Africa Group Limited (ABSA), Standard Bank Investment Corporation Limited, FirstRand Holdings Limited and Nedbank Limited. The study was based on the fact that, because the banking industry is usually a complex and competitive industry, these banks needed to overcome the challenge of catering for the unbanked segment to ensure their survival. Rootman et al. (2007) discovered that customer relationship management depended on three variables. These variables were attitude, knowledgeability and two-way communication.

According to Rootman et al. (2007), in a bank, two-way communication refers to the communication from bank management to clients and vice versa. Accordingly, the increasing need to manage relationships with consumers had revealed a wide variety of new marketing models which could be labeled as customer-focused, market-driven, one-on-one marketing, relationship marketing and integrated marketing communication forms. In the view of Rootman et al. (2007), each of these "new" marketing approaches emphasised the importance of two-way communication.

For Rootman et al. (2007), for the purpose of the research, two-way communication referred to the degree of appropriate and sufficient communication from a bank's management to clients, and vice versa. For Rootman et al. (2007), the importance of two-way communication in the banking industry cannot be disputed because in their study, the changing role of bank employees was evident. The evidence was in the fact that besides financial counseling, the banks needed to possess outstanding communication, incorporating listening and persuasion skills. At the end of the study, the researchers concluded that there existed a relationship between the perceived two-way communication of these banks and the effectiveness of customer relationship management strategies as part of the communication plan in the banks. The aspect of the two-way symmetrical communication being dialogic is supported here. This study looked out for the elements of two-way communication and feedback in the communication strategies employed by the Ghana Commercial Bank and Unibank Ghana Limited.

\subsection{Communication Strategy and Maintaining Bank-Client Relationships}

In another study to find out new trends of multi-dialogue communication in banks by Vojtovič and Dubček (2004:20) from the University of Trenčín in Slovakia, they discovered that, competition for market share in the banking industry required an ongoing search for new and more effective instruments of marketing communication, hence the need for banks to develop effective communication strategies.

The study revealed that the banks communicated messages about new products and services to clients through advertising on television, radio, in brochures and on their websites. Telephone calls were used to send this same message to high profiled clients. The banks had call centres where clients called in to table their concerns. The establishment of these call centres "was certainly a step in the right direction as it enabled the banks to get closer to the customer" (Vojtovič and Dubček, 2004:22). The banks further used sales channels to communicate with clients and this enabled them to take advantage of corresponding free capacities such as the opportunity to inform clients on new products and services (Vojtovič and Dubček, 2004).

Vojtovič and Dubček (2004) concluded that the battle for customers was getting more difficult as the years went by. Greater market saturation always led to a sharpening of competition. Essentially, one bank gaining new customers became possible only through another bank losing customers. A rule that the introduction of correct measures brought about strong customer relations and at the same time brought in new customers seemed to apply hence the need for communication (Vojtovič and Dubček, 2004). Based on the findings of Vojtovič and Dubček (2004), the banks communicated to their publics messages about new products and services to corporate clients through advertising on television, radio, in brochures and on their websites. For clients engaged in small and medium scale business with low literary skills, bank officials and the radio were used as channels. This study similarly tried to find the channels through which Unibank Ghana Limited and Ghana Commercial Bank communicated key issues or bank information including messages about new products and services to their informal sector clients.

In another study, Silver and Vegholm (2009) from the Centre for Banking and Finance, The Royal Institute of Technology, Stockholm, Sweden undertook a research on dyadic bank-SME relationship customer adaptation in interaction, role and organisation. The research aimed to analyse the Swedish banks' ability to meet the needs of their informal sector clients (SME customers).The analysis involved examining the interaction/communication process between the two parties, determining how the role of bankers was perceived and how the banks as organisations 
functioned. In the study, a total of 60 interviews were conducted, of which 45 were conducted with informal sector / SME clients. Thus, data was drawn from the in-depth interviews conducted with SME owners and with the three banks sampled.

The Swedish study was conducted in Norrtalje, a small municipality. It had about 50,000 inhabitants, approximately 17,000 of whom were concentrated in the city centre. The main purpose of the research was to investigate how support from banks influenced the creation and development of small firms mostly in the informal sector. The respondents were selected using a snowball-sampling technique, which involved asking the first respondent who had been chosen for the study to suggest other respondents whom they believed could be of interest.

The interaction process appeared to be a rather disordered affair and was characterised by a lack of communication between the banks and their informal/SME customers, resulting from two parties with different expectations of each other. Beside the banks' communication strategies, the SMEs preferred to have frequent and personalised contact with their banks. However, the empirical findings of the study clearly indicated that the informal sector/SME clients found it difficult to get in touch with their bankers when needed. As a result, many of the clients considered switching banks.

The findings similarly suggested that the banks sometimes offered advisory services to their informal sector clients which were being sought extensively by individuals and SME clients who found themselves in the informal sector. The informal sector clients interviewed for the study, however, revealed that they were unable to receive the advice they needed from their banking institutions because the individual bankers (officers) lacked the necessary knowledge and competence.

Another strategy used by the banks was communicating the technical aspects of loans and recommending different bank products and services to the informal sector client. With this strategy, SME customers often perceived bankers, who were referred to as business advisors, as "salespeople". This perception was in line with earlier research criticising individual bankers for acting more like salespeople than business advisors. And so rather than focusing on needs of their clients, bankers tended to promote the new products and services.

\section{Method}

\subsection{Study Site}

The study sites were in three groups. The first group comprised the head offices of Unibank Ghana Limited and Ghana Commercial Bank. The second group comprised the Ashaiman, Makola and Tema branches of Unibank Ghana Limited and Ghana Commercial Bank. And the third group was made up of the Makola, Tema and Ashaiman markets. Unibank Ghana Limited is a privately owned Ghanaian Bank and Ghana Commercial Bank is owned by the Ghanaian government.

\subsection{Study Design}

Qualitative research was undertaken in Accra, Ghana between October 2011 and May 2012. The individual in-depth interview was used. For this study, the purposive sampling was used because the study required only those in charge of communication in the bank (the public relations managers and the marketing managers) were interviewed.

\subsection{Sampling and Sampling Size}

The data gathered included taped interviews with six informants: two public relations managers, two marketing managers and two SME unit heads from both banks. Employees who had direct contact with clients were interviewed. Aside the 6 earlier interviews, a total of 32 interviews were conducted, of which 20 were with the informal sector clients/ SME clients from both banks and 12 were with relationship managers from both GCB and UGL. For this specific study, data was drawn from in-depth interviews conducted with SME owners, the relationship managers of three branches from each bank and three people from the communications department from the banks.

Table 1. Informants for Research

\begin{tabular}{llll}
\hline Category of Informant & Bank & Number & Location \\
\hline Public Relations Manager & Ghana Commercial Bank & 1 & Head Office, Accra \\
Public Relations Manager & Unibank Ghana Limited & 1 & Head Office, Circle \\
Marketing Manager & Ghana Commercial Bank & 1 & Head Office, Accra \\
Marketing Manager & Unibank Ghana Limited & 1 & Head Office, Circle \\
SME Unit Head & Ghana Commercial Bank & 1 & Head Office, Circle \\
SME Unit Head & Unibank Ghana Limited & 1 & Head Office, Circle \\
Relationship Managers & Ghana Commercial Bank & 6 & Makola Branch, Accra \\
Relationship Managers & Unibank Ghana Limited & 6 & Ashaiman Branch \\
Informal Sector Clients & From both banks & 20 & Makola, Tema, Ashaiman \\
& & & Markets \\
\hline
\end{tabular}




\subsection{Data Source}

Data for this research was sourced from the annual reports of the banks for the year 2010 as they were the recent reports available. For this study the secondary data comprised annual reports for the two banks for the year 2010 and newsletters circulated within the bank in 2010. Information was obtained from the in-depth interviews conducted with the public relations managers, the marketing managers and the SME unit heads of both banks. Interviews were conducted with the relationship officers of both banks and some of their informal sector clients.

\subsection{Data Collection}

The length of each interview varied between one-and-a-half hours to two hours, and were recorded and later transcribed to avoid any misunderstandings. An outline with questions was used as a guideline during the interviews. The interviews were semi-structured even though some aspects were examined in-depth. The questions included the particular communication plan or technique the banks referred to when communicating with your informal sector clients, what the objectives in the communication plan was and what channels of mass communication were used, among others. After transcribing, a report was developed putting into perspective the themes and objectives outlined for the study.

\subsection{Data Collection Instruments}

An interview guide was developed and used in collecting information from the field. For this study the interview guide was very specific, with carefully worded questions and it encompassed the list of topics to be covered. The interview guide was not followed to the letter as the questions were not asked in the order they appeared on the guide. Rather, the researcher moved back and forth through the topic list based on the informant's responses. Responses gathered from the bank officials were put together in a report with that of the informal sector clients coded using the statistical package for social sciences (SPSS 6.0). This allowed for findings to be put in graphs, tables and charts for clear understanding. Just like the responses from the bank officials the documentary analyses were put in a report format highlighting important themes and issues peculiar to the research.

\subsection{Data Analysis}

The information obtained from three separate interviews of the public relations manager, the marketing manager and the SME unit manager of Ghana Commercial Bank and one interview of the corporate affairs/marketing/product development manager of Unibank Ghana Limited were reported in this study. These were in the form of narrations, inferences, analogies and analyses. Documentary analyses of annual reports and newsletters of both banks were also included in the findings.

After collecting the data, analyses were carried out thematically to meet the objectives of the study. The recordings were eighteen hours and fifteen minutes in total length and took 62 hours to transcribe. Data analysis of the in-depth interview was done using the research objectives as themes. Themes centred on the communication channels, strategies, issues or bank information that is communicated to the informal sector and the processes of designing the communication strategies by the various banks. After transcribing the recorded responses, the findings of the research were discussed with particular reference to theories, concepts, related works and themes earlier on discussed.

\section{Results}

\subsection{GBC'S Communication Strategies}

The first strategy discovered was the medium of communication. This referred to the various forms of media employed in carrying across messages to the informal sector client. To help describe this, an inventory of the various forms of media was developed and used. GCB considered the medium of communication very important to use in the bid to communicate with their informal sector clients. The inventory developed included most of the traditional modes of communication among which were television, radio, the print medium and billboards. Other forms of communication used were outreach programmes. These programmes were expected to enable the bank to get closer to the informal sector clients at specific business locations. As part of the strategy, information was communicated using the languages or dialect of that target group. This was to prevent any language barrier and encourage feedback from the clients. According to the public relations manager "we are able to foster a two-way symmetrical communication between them and the informal sector client".

Another communication strategy was organising periodic regional banking clinics for their informal sector clients. The banking clinics were organised once every year in every region to educate the informal sector client on bank processes, procedures, products and services. According to the Marketing Manager of GCB:

These clinics are organised to involve the informal sector client in banking operations while learning more about the bank through the give-and-take way of communicating.

Ghana Commercial Bank used this platform to dialogue with their informal sector clients while bringing on board the 
unbanked informal sector client in that particular region. For GCB, this was mostly an open forum where questions were asked and answers given. The feedback element was highly present in the format as a plethora of issues were discussed during these banking clinics and workshops. Issues that came up included structures and systems of the bank and some dynamics of the business world. Others included rules and regulations governing the bank that somehow affected the informal sector clients and trends in the business setting as well as selected topical issues affecting (negatively or positively) the informal sector client.

The bank employed the code-switching approach as a different strategy of communication when dealing with the informal sector client. Representatives of the bank in their interaction with the informal sector clients spoke in the local dialects predominant in a particular business area. The GCB prides itself in communicating clearly with the informal sector clients in languages and dialects easily understood by the client. They claimed "to watch their tone and pace of their sentences when communicating with the informal sector client either face to face or over the telephone". Where there were different groups of people gathered with different language preferences, the bank switched between languages to enable all present understand. Thus, they used a mixture of Twi, Ga, Ewe, and Hausa among other languages when reaching out to clients in the Makola market, one of the central markets in Accra, for example. This form of code-switching was to enable all clients present to understand exactly the message the bank was communicating.

Yet another strategy for GCB was periodic sponsorships and partaking in important occasions of towns and villages of which GCB was present. Festivals, durbars and important functions held in these towns had the Ghana Commercial Bank represented. Here, the communication came in the form of being given the opportunity to address all celebrants while presenting cash items to the town. Similarly, the bank mounted banking booths to allow the informal sector client table concerns and difficulties in assessing the bank's services and products. This, according to the bank "fostered a good relationship between the bank and the informal sector client".

\subsection{Unibank's Communication Strategies}

For Unibank Ghana Limited the mode of communication in communicating with the informal sector client was used as a strategy by UGL. A "Direct Consumer Contact Programme" was one of the many ways UGL used to communicate different forms of information to their informal sector clients. According to the marketing manager, "there is the element of feedback here as the traders are encouraged to speak and ask questions as we communicate with them in the language they understand". The bank, however, noted the importance of the traditional modes of communication which included television, radio, the print medium and billboards and as such employed these channels of communication.

For UGL, relationship managers who ensured that the bank's informal sector clients were well taken care of was a strategy they could not do without. The bank through the relationship managers took care of a portfolio of informal sector clients reaching them for account opening to credit assessment and recovery. The relationship managers, according to the public relations manager of UGL, meet market associations to reach a large number of people to save time.

Another strategy used by Unibank Ghana Limited was the code-switching approach to communication. Code-switching involves using dialects or languages as and when needed to facilitate understanding between the communicator and communicatee. For UGL, this was done to make sure that the informal sector client got a grip of and understood what the bank was trying to put across by way of information and the technicalities involved in the bank's operations. Awards had been won in the advisory category by the bank at the CIMG awards in the years 2003, 2004, 2006, 2007 and 2010. According to the marketing manager of UGL, this went to show the premium placed on advisory services thereby communicating effectively with the informal sector client". According to the public relations manager ${ }^{15}$ of UGL:

We don't just sell our banking products and services but we go a step further to act as financial consultants to our informal sector clients.

Organising banking clinics was another communication strategy UGL employed. UGL organised the banking clinics four times every year in the Western, Greater Accra and Ashanti regions. None was held in the northern part of the country as they had no presence in the region as at the time the research was conducted. UGL collaborated with other institutions that shared this same philosophy to meet the informal sector half way by way of dialogue. The various forms of media Unibank used were television, radio, billboards and sometimes the print medium. According to the bank, these forms of media were used to communicate with their informal sector client as the bank found the need to maintain a closely knit relationship with their informal sector clients. The bank claimed to be in need of feedback from clients to re-strategise, build consensus and a healthy relationship between the bank and the informal sector client. According to the bank, dialogue ran through their communication strategy. 
Table 2. Communication strategies used by GCB and UGL in communicating with the informal sector clients

\begin{tabular}{ll}
\hline Ghana Commercial Bank Strategies & Unibank Ghana Limited Strategies \\
\hline Medium & Direct consumer contact programme \\
Code switching & Relationship managers \\
Physical appearance & Code switching \\
Banking clinics & Banking clinics \\
Public relations activities: Sponsorships & \\
Group presentations & \\
Telephone calls & \\
\hline
\end{tabular}

\section{Discussion}

\subsection{Related Works and Research}

Typically the communication strategy employed by the banks was to involve clients in every communication strategy the banks had to use according to Kaplan's (1991) schema. This strategy was to include elements of feedback and dialogue as key to a mutually beneficial relationship between bank and client. This was exactly what GCB and UGL attempted to do in putting together their communications strategies and subsequently executed the strategies.

Rootman et al (2007), in a study of 3 South African banks, discovered that the banks made very good use of their relationship managers in communicating with their individual and SME clients in the informal sector. Rootman et al (2007) discovered that dialogue and the attention paid to feedback from these clients formed a bed rock of the bank-client relationship. Accordingly, UGL, believed in relationship management and as such had relationship managers, who interacted with the informal sector client on a daily basis. However, GCB's marketing manager said "we do not see that (relationship management) as a strategy but rather a necessity for every 21 st century bank who wants to grow in a competitive market".

Both banks, however, had a strategy of tailoring bank products and services to fit the needs of the informal sector client. For example, if the client wanted to have enough money on a business trip, the GCB smart card was proposed and when the client wanted money without visiting the banking hall, UGL's ATM card was suggested. The banks communicated in languages their clients understood, to enable the client appreciate the bank's products and services better and be well informed". The informal sector clients interviewed also listed radio as a source of their bank information. Those who had access to television on a constant basis revealed that they got their information from there. They highlighted that messages from these channels were in local languages they could understand. They cited the relationship managers as also communicating with them in the languages they could understand and give feedback.

Inability by any bank to segment its publics would mean sending wrong messages to the wrong target groups. In Smart's (2000) study of the Bank of Canada, he highlighted how the bank carefully segmented its public in order to communicate effectively to these groups. His findings showed that the bank segmented its publics into various social groups (clients), stakeholders and the general public. This segmentation according to Smart (2000) enabled the bank to carve specific messages for specific publics.

Similarly, from the findings, after careful segmentation of their clients, banking clinics were organised for the various categories of clients. Information communicated by GCB and UGL to their informal sector clients included bank products and services, loan acquisition processes, interest rates, base rates as well as ATM card acquisition, its usage and charges. With the informal sector the website and emails were never options the banks considered in sending across messages. This was due to low level of literacy among the informal sector clients. The banks mainly relied on telephone calls and regular visits to introduce new products and services to the clients and also send other bank information to the informal sector clients. The bank information was communicated to the clients to keep them in the known of various changes as and when they occurred. The clients explained that the banking clinics were a way to get some salient questions answered. According to them some of the information they hear on radio and TV are corroborated at these banking clinics. Hence they are assured of the information they are being fed with.

Various communication strategies had been put in place by these banks in communicating with these segments. According to the banks, using the same communication strategy for the different segments of clients would be inappropriate and ineffective. This was due to fact that they may all have different needs, different levels of perception, different levels of education, different cultural levels and different levels of information processing. GCB and UGL therefore designed products and services after careful consideration of these factors.

\subsection{Theory and Research}

In employing the two way symmetrical model of communication according to Grunig and Hunt (1992), organisations understand the values, attitudes and beliefs of their publics. This is to foster effective communication by knowing for example the literacy level of the informal sector clients and their values as GCB and UGL did. By knowing these, the 
banks were able to couch messages to suit the attitudes, understanding and values of the informal sector client. Again to ensure effective communication between the bank officials and the informal sector client, the language that the client is most comfortable with must be used. The banks therefore employ the approach of code switching in their dialogue with these clients. Giles (1971) substantiates this by stating that code switching signals agreement and liking and creating greater rapport with conversational partners such that they approve of us more.

\section{Conclusion}

The study took into consideration the various elements considered by the Ghana Commercial Bank and Unibank Ghana Limited Ghana in designing their communication strategies, with the main purpose of discovering the strategies used by the banks in communicating with their informal sector clients. Because both banks had different missions, visions and values, they used communication peculiar to their organisational structure and culture. The chapter therefore looked at similarities and differences in the strategies used by both banks. Finally, both banks segmented their informal sector clients as well the means of communicating with these segments which included telephone calls and personal visits.

The study looked at the individual communication strategies used by the Ghana Commercial Bank and Unibank Ghana Limited in communicating with the informal sector client as a way of fostering dialogue in building a mutually beneficial business relationship with them. These strategies included the channel of communication, the kind of language used, employing relationship mangers to manage each client as well as tailoring products and services that met the banking needs of the informal sector client. The study again looked at how the relationship officers of both banks communicated with their informal sector clients while corroborating these claims from the informal sector clients themselves.

The informal sector clients corroborated assertions from the relationship managers, in the areas of the medium used in communication, the various public relations tools used and using telephone calls to pass on information. Though views from the informal sector clients corroborated this assertion, they preferred visits and telephone calls from the relationship managers when the need arose for them to be communicated with. According to the informal sector clients, they preferred to have frequent and personalised contact with their banks through bank officials. And the telephone calls and regular visits from the relationship managers made this possible.

\section{Acknowledgement}

I am deeply grateful to Prof. Nana Ansu Kyeremeh for his advice, contribution and for supporting me during this research. His valuable suggestions helped me through the completion of this research. I would like to thank officials of the Ghana Commercial Bank and Unibank Ghana Limited especially Nana Duncan, Mr. Kwarteng, Mr. McAddy and Mr. Amo for their immense help. May the lord cause his face to shine upon you.

\section{References}

Brettschneider, F. (2010). The peninsula, 15(4741), 46. http.thepeninsulaqatar.com /pdf/176-thepeninsulaseptember29.htm

Cornelissen, J. (2004). Corporate communications: Theory and practice. London: Sage Publications.

Giles H. (1973). Accommodation theory: Some new directions. Yorke Papers in Linguistics, 9, 105-136.

Grunig, J. (2001). Two-way symmetrical public relations: Past, present and future. In Heath, R. (2001) (Ed.), Handbook of Public Relation, Thousand Oaks, CA: Sage, 11-30. http://dx.doi.org/10.4135/9781452220727.n1

Hart, K. (1973). Informal income opportunities and urban employment in Ghana. Journal of Modern African Studies, 11, 61-89. http://dx.doi.org/10.1017/S0022278X00008089

Muwonge, A., Obwona, M., \& Nambwaayo, V. (2007). Enhancing contribution of the informal sector to national development: The case of Case of Uganda. Economic Policy Research Centre. Occasional Paper No. 33.

Rootman, C. T., \& Bosch, J. M. (2007). Variables influencing the customer relationship management of banks. Journal of Financial Services Marketing, 13(1), 52-62. http://dx.doi.org/10.1057/fsm.2008.5

Silver, L., \& Vegholm, F. (2009). The dyadic bank-SME relationship: Customer adaptation in interaction, role and organisation. Journal of Small Business and Enterprise Development, (16), 615-627. http://dx.doi.org/full/10.1108/14626000911000956

Vojtovič, S., \& Dubcek, A. (2004). New Trends of Multi-Dialogue Communication in Banks Biatec. Journal of banking, $12(1), 20-22$.

\section{(cc) $\mathrm{BY}$}

This work is licensed under a Creative Commons Attribution 3.0 License. 